\title{
In Vitro Analysis of the Interaction of Pseudomonas savastanoi pvs. savastanoi and nerii with Micropropagated Olive Plants
}

\author{
Luis Rodríguez-Moreno, Araceli Barceló-Muñoz, and Cayo Ramos
}

First and third authors: Área de Genética, Facultad de Ciencias, Universidad de Málaga, Campus de Teatinos s/n, E-29071, Málaga, Spain; and second author: IFAPA, Centro de Churriana (CICE Junta de Andalucía), Cortijo de la Cruz s/n, 29140-Churriana, Málaga, Spain. Accepted for publication 25 March 2008.

\begin{abstract}
Rodríguez-Moreno, L., Barceló-Muñoz, A., and Ramos, C. 2008. In vitro analysis of the interaction of Pseudomonas savastanoi pvs. savastanoi and nerii with micropropagated olive plants. Phytopathology 98:815-822.

This study assessed the use of in vitro olive plants to evaluate the virulence of Pseudomonas savastanoi pv. savastanoi strains isolated from olive and P. savastanoi pv. nerii strains isolated from oleander knots. First, different olive isolates were inoculated into stem wounds and differences in knot formation and weight of overgrowths were observed for the selected strains. Tissue proliferation was clearly visible in all inoculated plants 30 days after inoculation. Virulence of $P$. savastanoi pv. nerii mutants with defects in regard to biosynthesis of indole-3-acetic acid and/or cytokinins was tested using this system. In agreement with data previously reported, all mutant strains multiplied in olive but induced attenuated symptoms. To analyze the virulence of $P$. savastanoi pv. savastanoi
\end{abstract}

ABSTRACT

The gram-negative plant-pathogenic species Pseudomonas syringae is comprised of at least 50 pathovars that can be distinguished by their host range. $P$. syringae pathovars and related pathogens, such as those belonging to $P$. savastanoi, infect a wide range of herbaceous and woody plants causing diverse symptoms, such as leaf spots and blights, soft rots of fruits, wilts, overgrowths, scabs, and cankers (16). During the last few years, research on diseases caused by pseudomonads in herbaceous plants has progressed rapidly and the application of molecular genetics has provided new insight into pathogenicity and virulence determinants. The complete genome sequence of $P$. syringae pvs. tomato (4), phaseolicola (19), and syringae (13) has been determined. Comparative genomic analysis among these pathovars has not only revealed conserved components of the $P$. syringae core genome, but also those components unique to each pathogen. However, there is a general lack of knowledge concerning the virulence and pathogenicity determinants specific for infection of woody plants, including fruit trees. Examples of this are the determinants involved in bacterial canker of stone fruit caused by $P$. syringae pv. syringae and $P$. syringae pv. morsprunorum; olive knot caused by $P$. savastanoi pv. savastanoi; and apical necrosis of mango caused by $P$. syringae pv. syringae (20).

P. savastanoi pvs. savastanoi, fraxini, and nerii (14) cause knots and galls on members of the various genera of Oleaceae (including olive, ash, jasmine, and Phyllyrea spp.) and oleander (Nerium oleander L.). Symptoms of infected trees include overgrowths (tumorous galls or knots) on the stems and branches of the host plant and occasionally on the leaves and fruit. Olive

Corresponding author: C. Ramos; E-mail address: crr@uma.es

doi:10.1094/PHYTO-98-7-0815

(C) 2008 The American Phytopathological Society affected in their ability to grow in olive tissue, a $\operatorname{trp} E$ tryptophan auxotroph mutant was generated using a collection of signature tagged mutagenesis transposons. Virulence of this mutant was clearly reduced as evidenced by swelling of the olive tissue that evolved into attenuated knots. Furthermore, mixed infections with its parental strain revealed that the wild-type strain completely out-competed the $\operatorname{trp} E$ mutant. Results shown here demonstrate the usefulness of in vitro olive plants for the analysis of $P$. savastanoi pvs. savastanoi and nerii virulence. In addition, this system offers the possibility of quantifying virulence differences as weight of overgrowths. Moreover, we established the basis for the use of mixed infections in combination with signature tagged mutagenesis for high-throughput functional genomic analysis of this bacterial pathogen.

Additional keywords: anthranilate synthase, Olea europaea, olive knot disease, phytohormone, tryptophan biosynthesis.

and oleander strains of $P$. savastanoi differ from one another in biochemical and genetic characteristics, as well as in host specificity. In artificial infections, strains of $P$. savastanoi pv. nerii are virulent on both oleander and olive, whereas those of $P$. savastanoi pv. savastanoi only induce knots on olives $(18,39,40)$.

The development of olive and oleander galls is dependent on bacterial production of indole-3-acetic acid (IAA) and cytokinins (Ck) $(17,24,37)$. In $P$. savastanoi, IAA is synthesized from $L$ tryptophan in two steps catalyzed by the products of the iaaM and $i a a H$ genes, tryptophan monooxygenase and indole acetamide hydrolase, respectively (9). Both iaaM and iaaH form an operon, which is generally plasmid encoded in $P$. savastanoi pv. nerii strains and localized in the chromosome in most $P$. savastanoi $\mathrm{pv}$. savastanoi strains $(7-9,32)$. With the exception of the requirement of a functional hypersensitive response and pathogenicity type III secretion system $(35,36)$, no other virulence factors have been identified for this pathogen. Recently, we have reported the selection of several genetically pliable olive knot isolates (31); however, functional genomic analysis of $P$. savastanoi pv. savastanoi strains, as well as many other $P$. syringae pathovars that can infect fruit trees, still requires the development of pathogenicity and virulence tests allowing for expensive, fast, and reliable screening of a large number of mutant strains.

Pathogenicity tests for $P$. savastanoi pvs. savastanoi and nerii strains are usually performed on 1- to 3-year-old olive or oleander plants wounded on the main stem or lateral branches and grown for several months in a greenhouse at room temperature $(22,28$, $30,35)$. Aside from the space required for plant maintenance and the long period of time necessary for recording symptoms, usually between 2 to 3 months after inoculation, plant growth under noncontrolled light, humidity, and temperature conditions often results in large variability in size and number of knots developed. Other less frequently used methods include inoculation 
of $P$. savastanoi pathovars cells on leaf surfaces of growing olive (38) and oleander plants $(37,39)$ and inoculation on the midvein of oleander leaf fragments kept at $26^{\circ} \mathrm{C}$ under constant lighting (28).

In vitro techniques are widely used to study pathogenicity and virulence of animal bacterial pathogens and can be usefully applied in plant pathology. To date, several techniques for micropropagation of a great number of fruit trees, including several olive varieties $(6,25,33)$, have been described, facilitating mass production of clonal and disease-free plants that can be easily maintained under controlled conditions in a growth chamber. This study assesses the use of in vitro olive plants to study pathogenicity and virulence of $P$. savastanoi pvs. savastanoi and nerii. Since it is likely that there is a very close link between biosynthesis of tryptophan, the precursor of IAA, and P. savastanoi pv. savastanoi virulence, we decided to isolate and test, using our model system, the behavior of $P$. savastanoi pv. savastanoi tryptophan auxotroph mutants. The results presented encourage future utilization of in vitro olive plants, in combination with signature tagged mutagenesis and competitive index analysis, for highthroughput functional genomic analysis of $P$. savastanoi pathovars.

\section{MATERIALS AND METHODS}

Bacterial strains and growth media. Strains of $P$. savastanoi pvs. savastanoi and nerii used in this study are listed in Table 1. $P$. syringae pv. tomato DC3000 (4) was used as a negative control in pathogenicity experiments on olive plants. All the strains were routinely grown in King's medium B (KB) (21) at $28^{\circ} \mathrm{C}$, LuriaBertani (LB) agar (27), or standard succinate medium (SSM) (26). For the selection of P. savastanoi pv. savastanoi tryptophan auxotrophs, SSM was supplemented with $L$-tryptophan at $40 \mu \mathrm{g} / \mathrm{ml}$. Solid and liquid media were supplemented, when required, with the following antibiotics: kanamycin $(\mathrm{Km})$ at 25 or $50 \mu \mathrm{g} / \mathrm{ml}$ and nitrofurantoin (Nf) at $100 \mu \mathrm{g} / \mathrm{ml}$.

Micropropagation of olive. Micropropagated olive (Olea europaea L.) plants were derived from an in vitro germinated seed, collected from plant cv. Arbequina, established in DriverKuniyuki walnut (DKW) medium (11) supplemented with sucrose at $20 \mathrm{~g} /$ liter and myo-inositol at $1 \mathrm{~g} /$ liter as carbon source; $\mathrm{pH}$ was adjusted to 5.74 before adding the gelling agent and autoclaving the medium at $121^{\circ} \mathrm{C}$ for $15 \mathrm{~min}$. Apical shoots and nodal sections with lateral buds were transferred for proliferation to DKW medium containing $30 \mathrm{~g}$ of sucrose, $0.1 \mathrm{ml}$ of indolebutyric acid

TABLE 1. Pseudomonas savastanoi pvs. savastanoi and nerii strains used in this study

\begin{tabular}{|c|c|c|c|}
\hline $\mathrm{Name}^{\mathrm{a}}$ & Origin & $\begin{array}{l}\text { Relevant } \\
\text { phenotype }^{b}\end{array}$ & $\begin{array}{l}\text { Original source/ } \\
\text { reference }\end{array}$ \\
\hline \multicolumn{4}{|c|}{ P. savastanoi pv. savastanoi } \\
\hline IVIA1628-3 & Spain & IAA $^{+}$ & IVIA \\
\hline CFBP 2074 & Algeria & $\mathrm{IAA}^{+}$ & M. N. Yahiaoui \\
\hline NCPPB 1344 & USA & $\mathrm{IAA}^{+}$ & E. Wilson \\
\hline NCPPB 3335 & France & $\mathrm{IAA}^{+}$ & D. E. Stead \\
\hline Psv-Trp1 & France & $\begin{array}{l}\text { Trp }^{-} \text {trpE mutant } \\
\text { isolated from } \\
\text { NCPPB } 3335\end{array}$ & This study \\
\hline ITM317 & Italy & $\mathrm{IAA}^{+}$ & (39) \\
\hline \multicolumn{4}{|c|}{ P. savastanoi pv. nerii } \\
\hline ITM519 & Italy & $\mathrm{IAA}^{+} / \mathrm{Ck}^{+}$ & (39) \\
\hline ITM519-6 & Italy & $\mathrm{IAA}^{-} / \mathrm{Ck}^{-}$ & (17) \\
\hline ITM519-7 & Italy & $\mathrm{IAA}^{-} / \mathrm{Ck}^{+}$ & (17) \\
\hline ITM519-41 & Italy & $\mathrm{IAA}^{+} / \mathrm{Ck}^{-}$ & (17) \\
\hline
\end{tabular}

${ }^{a}$ IVIA, Instituto Valenciano de Investigaciones Agrarias Collections, Valencia, Spain; NCPPB, National Collection of Plant Pathogenic Bacteria, York, United Kingdom; and CFBP, Collection Francaise des Bacteries Phytopathogenes, Angers, France.

b IAA, indole-3-acetic acid; Ck, cytokinins; Trp, tryptophan; +, production; and -, nonproduction.
(IBA) $(0.1 \mathrm{mg} / \mathrm{ml})$, and $10 \mathrm{ml}$ of benzyl adenine (BA) $(0.1 \mathrm{mg} / \mathrm{ml})$ and stored for 2 month in a growth chamber at $25 \pm 1{ }^{\circ} \mathrm{C}$ and $16 \mathrm{~h}$ photoperiod. Four- to five-nodal explants were transferred to DKW rooting media containing $20 \mathrm{~g}$ of sucrose and $1 \mathrm{ml}$ of IBA $(0.1 \mathrm{mg} / \mathrm{ml})$. To avoid negative effect of light on rooting, explants were maintained in the dark for 2 weeks at $25 \pm 1{ }^{\circ} \mathrm{C}$ and then transferred and maintained in a growth chamber for two more weeks at the same temperature under $16 \mathrm{~h}$ photoperiod. Finally, rooted explants were transferred to DKW media without hormones and kept for at least two more weeks in a growth chamber under the same light and temperature conditions prior to inoculation. In vitro olive plants used in this work were 60 to $80 \mathrm{~mm}$ long (stem diameter 1 to $2 \mathrm{~mm}$ ) and contained three to five internodal fragments.

Plant inoculation and isolation of bacteria from olive knots. In vitro olive plants were wounded by excision of an intermediate leaf and inoculated at different cell densities of bacteria under sterile conditions. One hundred microliters of overnight LB cultures of bacteria was deposited on a nitrocellulose filter (pore size $0.22 \mu \mathrm{m}$ ) that was on the surface of an LB medium plate and incubated at $28^{\circ} \mathrm{C}$ for $48 \mathrm{~h}$. Bacterial cells were suspended in $1 \mathrm{ml}$ of $10 \mathrm{mM} \mathrm{MgCl}_{2}$, and cell suspensions were adjusted turbidometrically to densities of ca. $10^{7}$ colony forming unit $(\mathrm{CFU}) / \mathrm{ml}$ $\left(\mathrm{OD}_{600 \mathrm{~nm}}=0.1\right)$. Concentrations of $10^{3}$-fold in $10 \mathrm{mM} \mathrm{MgCl}_{2}$ were prepared when appropriate, and $1 \mu$ of the resulting cell suspensions was used to inoculate wounds with approximately $10^{7} \mathrm{CFU}$. Tenfold dilutions in $10 \mathrm{mM} \mathrm{MgCl}$ were prepared and used to inoculate plants with ca. $10^{2}$ to $10^{6} \mathrm{CFU}$ per wound. Plants were incubated in a growth chamber at $25 \pm 1^{\circ} \mathrm{C}$ and a $16 \mathrm{~h}$ photoperiod. After different periods of time, P. savastanoi pv. savastanoi cells were recovered from inoculated explants as follows. Stem fragments were sampled $1 \mathrm{~cm}$ above and $1 \mathrm{~cm}$ below the inoculation point and weighed. After removal of the leaves, samples were crushed in a mortar with $1 \mathrm{ml}$ of $10 \mathrm{mM}$ $\mathrm{MgCl}_{2}$. Serial dilutions of the obtained suspensions were spotted on $\mathrm{KB}-\mathrm{Nf}$ and incubated at $28^{\circ} \mathrm{C}$ for 2 days. Weight of overgrowths and population densities are the mean of at least three replicates. Statistical analysis of stem weight and population densities were carried out using the Student's $t$ test $(\alpha=0.05)$.

Symptoms induced on inoculated olive plants were visualized with a stereoscopic fluorescence microscope (Leica MZ FLIII). Images were captured with a high-resolution digital camera (Nikon DXM 1200) and processed for display using Adobe Photoshop CS software.

Isolation of tryptophan auxotrophs by transposon mutagenesis. Transposon mutagenesis of $P$. savastanoi pv. savastanoi strain NCPPB 3335 with Tag-mini-Tn5-Km2, a collection of transposons designed for signature tagged mutagenesis (STM) (15), was performed by biparental mating as previously described (31). Cells from the donor strain Escherichia coli S17- $\lambda$ pir and the recipient strain were mixed in a $1: 3$ proportion, respectively, and deposited on a nitrocellulose filter (pore size, $0.22 \mu \mathrm{m}$ ) that was on the surface of an LB medium plate. After $12 \mathrm{~h}$ incubation at $28^{\circ} \mathrm{C}$, the cells were resuspended in $0.9 \% \mathrm{NaCl}$ and plated on $\mathrm{KB}-\mathrm{Km}$. Nf was also added to counter-select for the donor strain. Integration of this transposon into the genome of $P$. savastanoi pv. savastanoi NCPPB 3335 occurs randomly and in most cases at a single site (31).

About 5,000 independent Tag-mini-Tn5-km2 transconjugants were tested for their ability to grow on SSM with or without tryptophan. Three tryptophan auxotroph mutants were selected and further characterized. The insertion point of the transposon into the genome of two of these mutants was determined by arbitrary polymerase chain reaction (PCR) as described below.

Competition analysis of $\boldsymbol{P}$. savastanoi pv. savastanoi tryptophan auxotroph Psv-Trp1. Virulence attenuation of $P$. savastanoi pv. savastanoi tryptophan auxotroph strain Psv-Trp1 $\left(\mathrm{Km}^{\mathrm{R}}\right)$ was assayed in mixed inoculations with its isogenic parental 
strain NCPPB 3335. Competitive index (CI) assays were performed essentially as described by Macho et al. (23). A mixed inoculum containing equal CFU (approximately $10^{4} \mathrm{CFU}$ ) of wild type and mutant strains was inoculated into olive stem wounds. Serial dilutions of the inoculum were plated onto LB agar and LB-Km to confirm dose and relative proportion between the strains, or the input mutant-to-wild-type ratio, which should be close to one. Bacteria were recovered from the infected plants at 30 days postinoculation (dpi) as described above, and serial dilutions of the obtained suspensions were spotted on LB agar and LB-Km. For in vitro CI assays in LB and SSM media, $200 \mu \mathrm{l}$ of mixed inoculum at $2 \times 10^{6} \mathrm{CFU} / \mathrm{ml}$, containing equal amounts of wild-type and mutant bacteria, was inoculated into $1.8 \mathrm{ml}$ of the corresponding media and grown for $24 \mathrm{~h}$ at $28^{\circ} \mathrm{C}$ with aeration. Serial dilutions were then plated onto LB agar and LB-Km to calculate the relative proportion between the strains. CI values are the mean of three replicates showing typical results of two independent experiments. Statistical analysis of CI values was carried out using the Student's $t$ test and the null hypothesis that mean index was not significantly different from $1.0(\alpha=0.05)$.

Recombinant DNA techniques. Recombinant DNA techniques were performed as described by standard procedures (34). Total DNA of $P$. savastanoi pv. savastanoi strain NCPPB 3335 was isolated from $1.5 \mathrm{ml}$ of stationary LB culture using the Jetflex Genomic DNA purification Kit (Genomed GmbH, Löhne, Germany).

Arbitrary PCR was performed as previously described $(5,12)$. Amplified DNA fragments were sequenced on both strands by the dideoxy sequencing termination method using ABI Prisms 310 (Applied Biosystem) sequencer and primers TNINT and ARB2 (12). Contiguous DNA sequences were assembled using Seqman (DNASTAR) and compared with sequences recorded in public databases using NCBI BLAST.

DNA labeling, hybridization, and detection were carried out using digoxigenin-labeling and detection kit (Roche Molecular Biochemicals). aphA DNA probe $(820 \mathrm{pb})$ was labeled by PCR using primers Km-aphA-F and Km-aphA-R and plasmid pUC18N-Km as DNA template (29).

\section{RESULTS}

Pathogenicity of $P$. savastanoi pv. savastanoi strains on in vitro olive plants. Pathogenicity of five virulent strains of $P$. savastanoi pv. savastanoi isolated from olive knots in different countries (Table 1) was tested on in vitro olive plants. Olive plants were inoculated with $10^{7}$ to $10^{8} \mathrm{CFU}$ of the corresponding strain per wound. P. syringae pv. tomato DC3000 was also inoculated as a negative control. While DC3000 induced a superficial necrosis of the plant tissue at the inoculation point (Fig. 1A), which was expected for the induction of a hypersensitive response, $P$. savastanoi pv. savastanoi strains induced the formation of diverse symptoms in all inoculated plants that were already distinguishable from control plants at $7 \mathrm{dpi}$. Figure 1 shows the symptoms developed by inoculation of the five strains tested at $30 \mathrm{dpi}$. Olive plants inoculated with $P$. savastanoi pv. savastanoi strains CFBP 2074 (Fig. 1B) and ITM317 (Fig. 1C) developed a rapid necrosis of the stem spreading both upwards and downwards from the inoculation point. At this time, none of these plants as well as the plants inoculated with strain IVIA 1628-3 (Fig. 1D) had developed evident knots. However, swelling of the stem was observed below the inoculation point on plants infected with strains ITM317 and IVIA 1628-3 (Fig. 1C and D, respectively). Nevertheless, average weight of overgrowths developed on plants inoculated with CFBP 2074 (27.6 mg), ITM317 (33.8 mg), or IVIA $1628-3(37.9 \mathrm{mg})$ was in all cases significantly different from that of mock control plants or stems inoculated with $P$. syringae pv. tomato DC3000 (12.5 mg) (Fig. 1G). In contrast, knot formation was clearly visible at $30 \mathrm{dpi}$ in plants inoculated with P. savastanoi pv. savastanoi strains NCPPB 1344 (Fig. 1E)
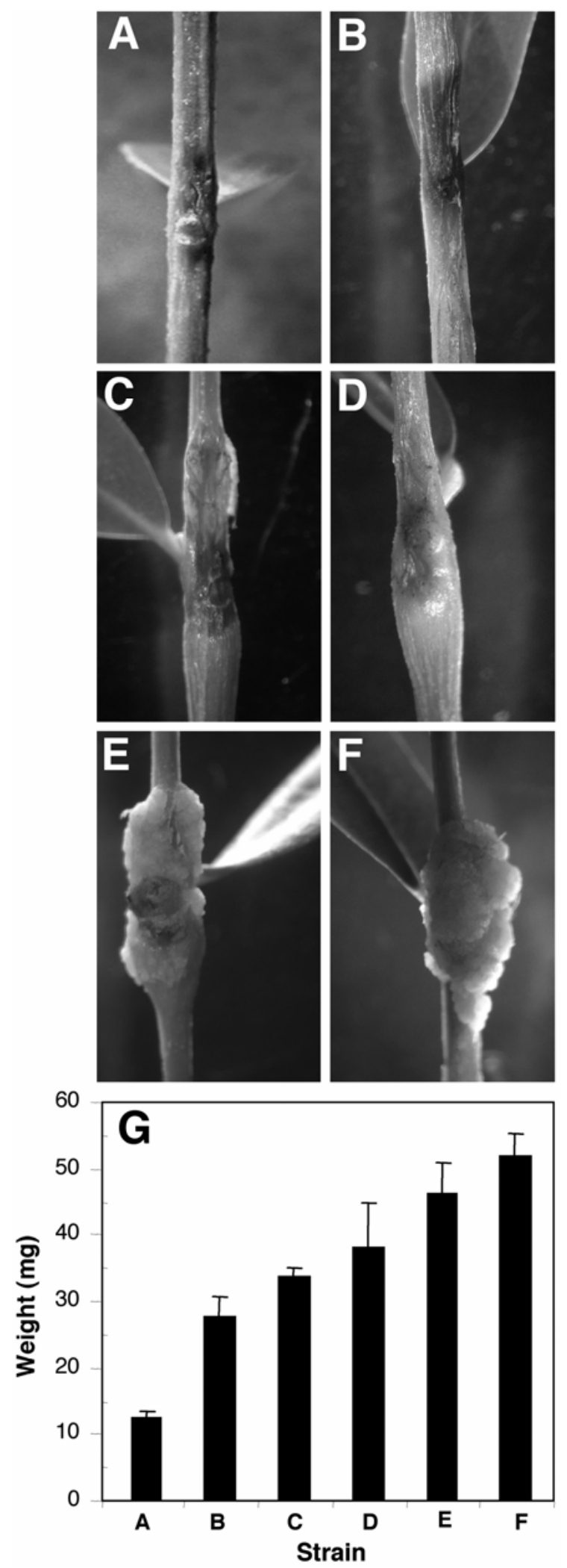

Fig. 1. Symptoms induced by Pseudomonas savastanoi pv. savastanoi strains on the stem of in vitro olive plants 30 days after inoculation of $10^{7}$ to $10^{8} \mathrm{CFU}$ of the corresponding strain. A, Negative control, $P$. syringae pv. tomato DC3000; B, CFBP 2074; C, ITM317; D, 1628-3; E, NCPPB 1344; and F, NCPPB 3335. G, Weight of overgrowths developed at 30 days postinoculation on the stem of plants inoculated with the indicated strain. Data represent the average of four independent plants. Error bars indicate the standard deviation from the average. Average weight of overgrowths induced by $P$. savastanoi pv. savastanoi strains was in all cases significantly different $(\alpha=0.05)$ from negative control plants. 
and NCPPB 3335 (Fig. 1F), although they varied in size, morphology, and weight. Average weights of overgrowths induced by these two strains were 46.0 and $52.0 \mathrm{mg}$, respectively (Fig. 1G).

Growth of $P$. savastanoi pv. savastanoi strains in olive plants. Two P. savastanoi pv. savastanoi strains inducing the development of different symptoms in micropropagated olive plants, ITM317 and NCPPB 3335, were selected to test their ability to grow and persist in plant tissues. Both bacteria were able to multiply in the olive tissue during the first week postinoculation when they were inoculated at a diluted suspension (about $10^{4} \mathrm{CFU}$ ) reaching around $10^{8}$ (ITM317, Fig. 2A) and $10^{7} \mathrm{CFU}$ (NCPPB
3335, Fig. 2B) at 7 dpi. In both cases, bacterial counts remained steady at these levels until the end of the experiment ( $28 \mathrm{dpi}$ ). When higher cell doses were used for inoculation $\left(10^{7}\right.$ to $\left.10^{8} \mathrm{CFU}\right)$, bacterial counts obtained 1 day after infection decreased slightly; however, in both cases, the number of bacteria increased again to the initial inoculation density at 3 dpi and remained steady at these levels at subsequent sampling times (Fig. 2A and B). Weight of overgrowths developed on plants inoculated with high cell doses of ITM317 increased slightly with time from approximately $27 \mathrm{mg}$ ( $1 \mathrm{dpi})$ to $34 \mathrm{mg}$ (28 dpi); however, average weights were not significantly different from those of stems
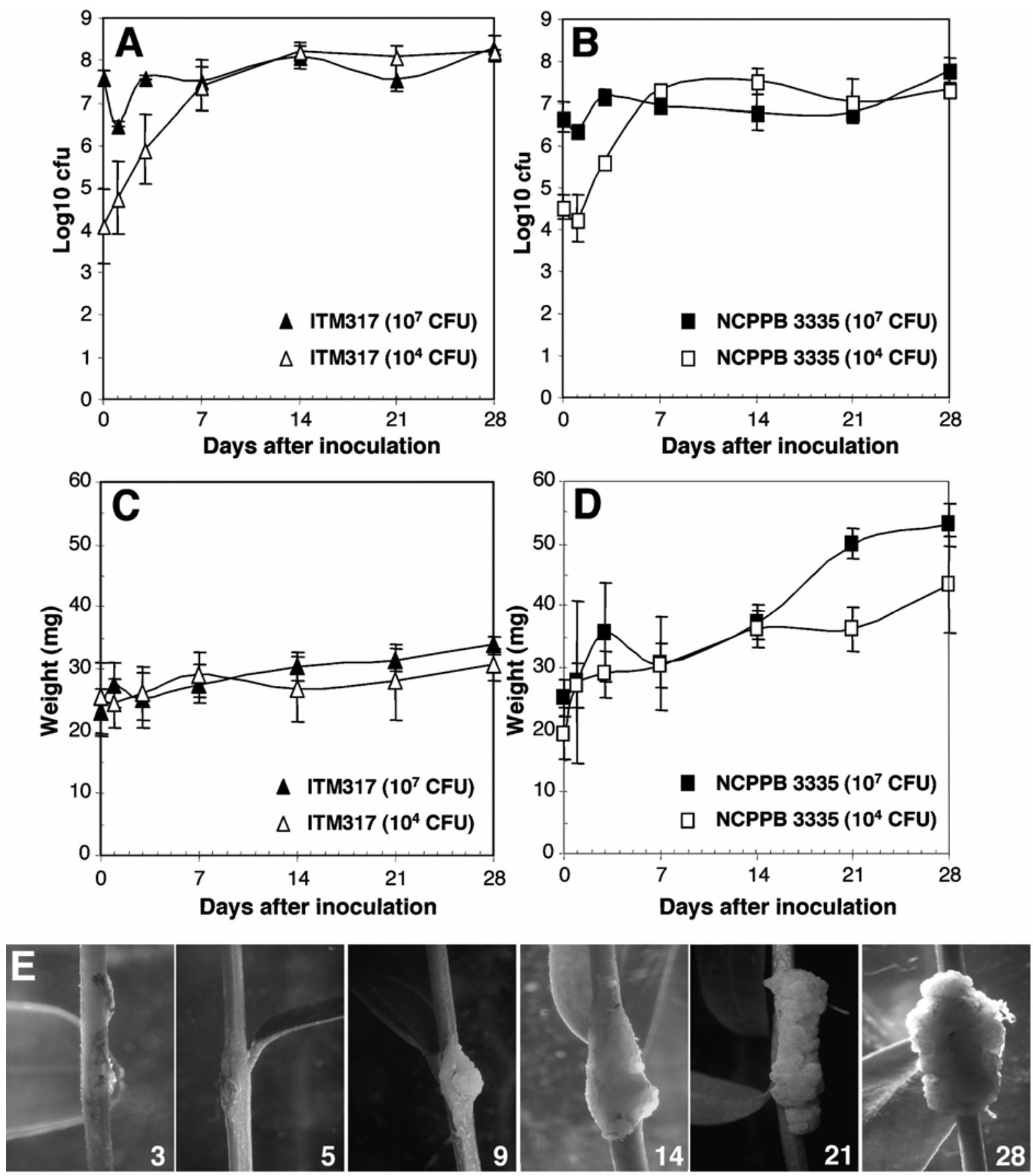

Days after inoculation

Fig. 2. Growth curves of Pseudomonas savastanoi pv. savastanoi strains A, ITM317 and B, NCPPB 3335 in in vitro olive stems. Weight of overgrowths induced by strains C, ITM317 and D, NCPPB 3335. Closed and open symbols correspond to inoculations with approximately $10^{7}$ and $10^{4}$ CFU, respectively. Data correspond to the total number of bacterial cells isolated from stem fragments covering $1 \mathrm{~cm}$ above and $1 \mathrm{~cm}$ below the inoculation point and represent the average of at least three independent experiments. A, B, C, and D, Values in brackets indicate the total number of bacterial cells inoculated. E, Evolution of olive knot symptoms on plants inoculated with $10^{7} \mathrm{CFU}$ of $P$. savastanoi pv. savastanoi NCPPB 3335. 
inoculated with $10^{4} \mathrm{CFU}$ of this strain at any time postinoculation (Fig. 2C). In contrast, weights of knots induced by NCPPB 3335 on plants inoculated with either of both cell doses were similar from 1 to $14 \mathrm{dpi}$ and significantly different at $21 \mathrm{dpi}$. Although at 28 dpi average weight of knots was higher on plants inoculated with $10^{7} \mathrm{CFU}\left(52 \mathrm{mg}\right.$ ) than on plants inoculated with $10^{4} \mathrm{CFU}$ $(43.5 \mathrm{mg})$ of this strain, significant differences were not found at this postinoculation time (Fig. 2D). Figure 2E shows the evolution of knot progression in plants inoculated with a high cell density of $P$. savastanoi pv. savastanoi $\mathrm{NCPPB} 3335$, which induced the formation of knots more indicative of field symptoms in micropropagated olive plants. Swelling of the stem tissue observed in these plants at 5 dpi was followed by the formation of hyperplastic knots already visible at 9 dpi.

Dose/response relationship for $P$. savastanoi pv. savastanoi strain NCPPB 3335. We chose strain NCPPB 3335 in order to determine the number of bacteria required for symptom development (knot formation). Olive plants were inoculated with this strain at six different levels of inocula (from approximately $10^{2}$ to $\left.10^{7} \mathrm{CFU}\right) ; 6$ to 10 plants were inoculated per cell dose. Swelling of the stem tissue at the wound site was already visible at $7 \mathrm{dpi}$ in plants inoculated with about $10^{4}$ to $10^{7} \mathrm{CFU}$; however, all plants developed visible overgrowths at $30 \mathrm{dpi}$. Although knot size increased with increasing cell densities of bacterial cells from $10^{2}$ to $10^{4} \mathrm{CFU}$, weight of overgrowths on plants inoculated with $10^{4}$ to $10^{7} \mathrm{CFU}$ was not significantly different at $30 \mathrm{dpi}$ (data not shown).

Virulence of $P$. savastanoi pv. nerii mutants defective in phytohormone production. $P$. savastanoi pv. nerii strains have also been reported to be able to infect olives $(18,39,40)$. On the other hand, the expression of IAA genes in P. savastanoi has been reported to be sufficient in initiating the development of knots on oleander and olive, while cytokinins are necessary for full expression of the disease symptoms and determining knot size $(17,37)$. The next experiments were aimed to test the pathogenicity of $P$. savastanoi pv. nerii strains defective in phytohormone production in olive plants grown in vitro. Wild-type $P$. savastanoi pv. nerii strain ITM519 and three mutants derived from this strain defective in the production of IAA (ITM519-7), Ck (ITM519-41), or both phytohormones (ITM519-6) were inoculated at high cell density $\left(10^{7} \mathrm{CFU}\right)$ into olive stems. In agreement with data previously reported using 1-year-old olive and oleander plants (17), virulence of the four tested strains was found to be different (Fig. $3 \mathrm{~A}$ and B). Inoculation of strain ITM519 ( $\left.\mathrm{IAA}^{+} / \mathrm{Ck}^{+}\right)$induced swelling of the tissue already observed at $7 \mathrm{dpi}$. As the swollen tissue continued to grow, typical knots were clearly visible at 30 dpi (average weight of knots $49.6 \mathrm{mg}$ ). Symptoms induced by mutant ITM519-41 ( $\mathrm{IAA}^{+} / \mathrm{Ck}^{-}$) were less severe. Swelling of the tissue evolved into attenuated knots showing a slight necrosis at 30 dpi. Although average weight of overgrowths induced by this strain $(42.3 \mathrm{mg})$ was lower than that of stems inoculated with the parental strain, average weights were not significantly different (Fig. 3A and B). Mutants ITM519-7 (IAA ${ }^{-} / \mathrm{Ck}^{+}$) and ITM519-6 $\left(\mathrm{IAA}^{-} / \mathrm{Ck}^{-}\right)$were slightly virulent since both strains induced a superficial necrosis of the plant tissue at the inoculation point (Fig. 3A). In addition, weights of overgrowths developed on plants inoculated with both mutant strains (from 15 to $18 \mathrm{mg}$ ) were significantly different from those of stems inoculated with the parental strain (Fig. 3B).

Multiplication of the different strains in olive tissue was tested for all the mutants in comparison with the wild-type strain. In agreement with data previously reported using oleander leaves (17), no significant differences in the population density in olive plants were observed at 30 dpi between the wild-type strain and

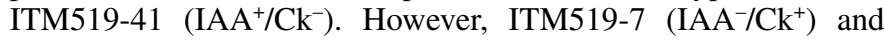
ITM519-6 $\left(\mathrm{IAA}^{-} / \mathrm{Ck}^{-}\right)$reached slightly higher cell densities than the parental strain (Fig. 3B).

Isolation and characterization of $P$. savastanoi pv. savastanoi tryptophan auxotroph mutants. About 5,000 independent Tagmini-Tn $5-\mathrm{km} 2$ transconjugants were tested for their ability to grow on SSM with or without tryptophan at $40 \mu \mathrm{g} / \mathrm{ml}$. Of these, three nonleaky $\operatorname{Trp}^{-}$mutant strains were isolated. While the wildtype strain was able to grow in both SSM and SSM-Trp, growth of the mutants in SSM was completely impaired. In contrast, growth rate of the mutants, determined in media supplemented with tryptophan at $40 \mu \mathrm{g} / \mathrm{ml}$ by OD measurements at $600 \mathrm{~nm}$ during the first $15 \mathrm{~h}$, was found to be similar to that observed for the wild-type strain (data not shown). To determine whether the wild type and the mutant strain yielded similar CFU titers in stationary phase, competitive index assays were performed in LB
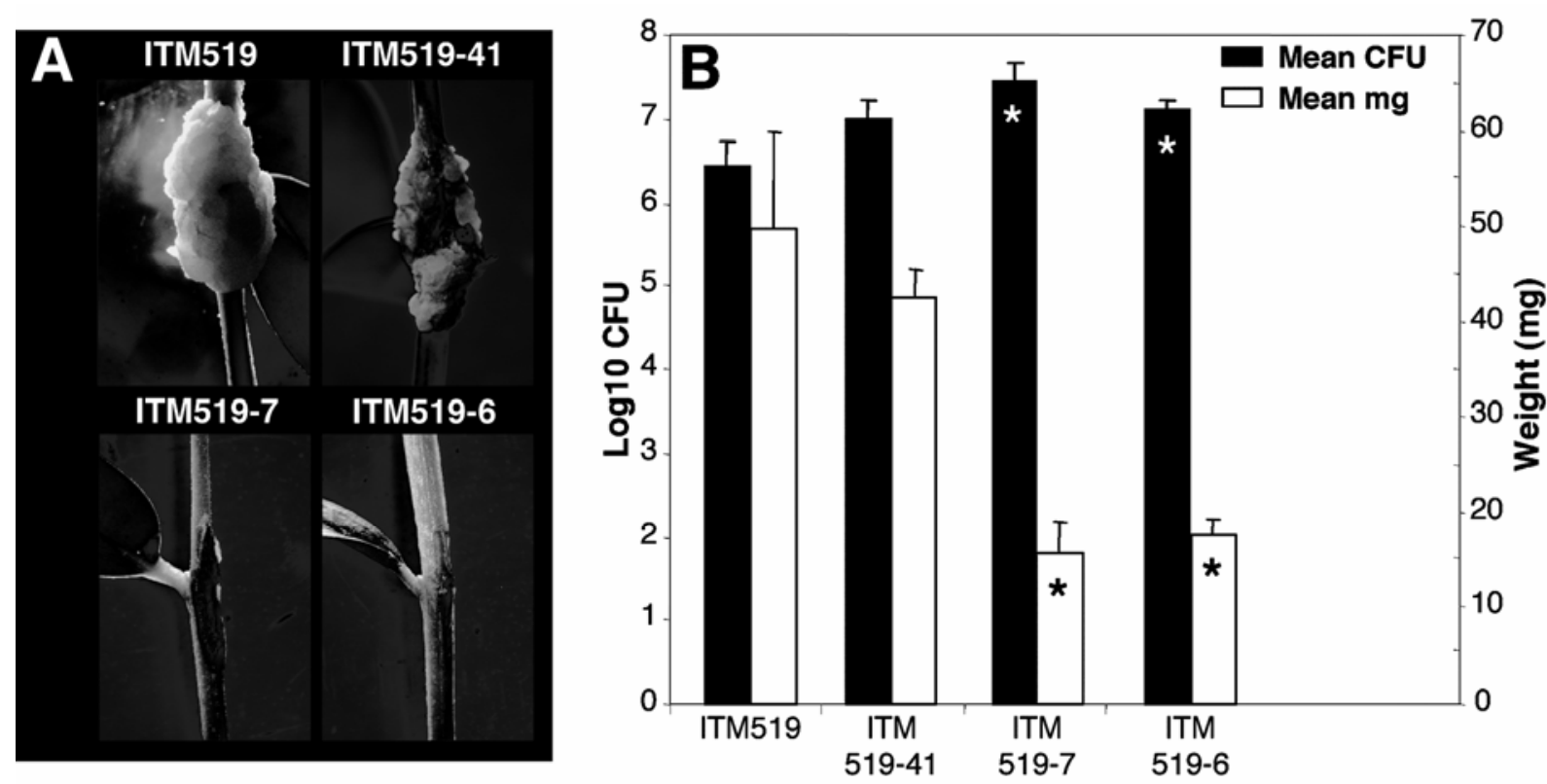

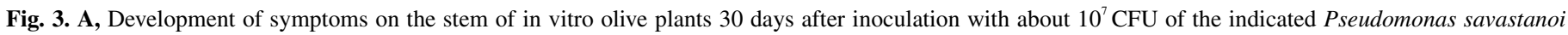

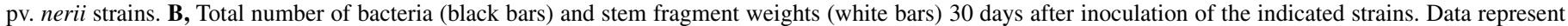

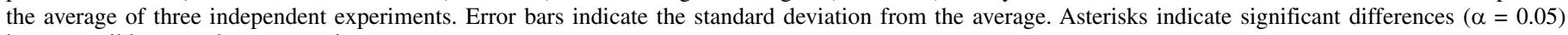
between wild type and mutant strains. 
and SSM media supplemented with and without different concentrations of tryptophan. In LB and LB supplemented with tryptophan at 50 or $100 \mu \mathrm{g} / \mathrm{ml}$, CI analysis showed a significant decrease in the number of CFU reached by the Psv-Trp1 mutant when compared with the wild-type strain. However, partial complementation of the tryptophan auxotrophy, although not significantly different from the parental strain, was observed in SSM containing either tryptophan at 50 or $100 \mu \mathrm{g} / \mathrm{ml}$ (Fig. 4A).

The insertion point of the transposon into the genome of two out of the three $\operatorname{Trp}^{-}$mutants isolated, Psv-Trp1 and Psv-Trp2, was determined by arbitrary PCR and sequencing. This technique allowed us to amplify DNA fragments containing $300 \mathrm{bp}$ (PsvTrp1) and $200 \mathrm{bp}$ (Psv-Trp2) regions that flank the transposon insertion site. Sequencing of the fragments and homology searches allowed us to unambiguously determine that in both mutants the insertion occurred in a gene showing 99 and $97 \%$ identity with the $\operatorname{trpE}$ gene of $P$. savastanoi pv. savastanoi (M55911) and $P$. syringae pv. phaseolicola (DQ127233), respectively. This gene encodes the $\alpha$-subunit of the anthranilate synthase enzyme which catalyses the first step in the biosynthesis of tryptophan. Hybridization of EcoRI- and EcoRV-digested total DNA of Psv-Trp1 and Psv-Trp2 against a transposon probe ( $a p h A)$ showed a single hybridization band, as expected for single insertions of the transposon into the genome of each mutant (data not shown).

Virulence of Psv-Trp1 on in vitro olive plants was clearly reduced in comparison to the wild-type strain. Single inoculations of Psv-Trp1 at both high $\left(10^{7} \mathrm{CFU}\right)$ and low $\left(10^{4} \mathrm{CFU}\right)$ cell doses induced swelling of the plant tissue; however, the swollen tissue evolved into attenuated hyperplastic knots that were only visible in plants inoculated with a high concentration of bacteria (Fig. 4B). In fact, average weight of knots induced by mutant Psv-Trp1 and its parental strain NCPPB 3335 were significantly different at both cells doses (Fig. 4C). Growth and survival of Psv-Trp1 in the olive tissue was clearly impaired. Cell extraction from knots developed at wound sites inoculated with $10^{7} \mathrm{CFU}$ of this strain only contained approximately $10^{3} \mathrm{CFU} 30$ days after infection. In addition, Psv-Trp1 cells (about $10^{2} \mathrm{CFU}$ ) could only be detected in symptomatic tissue of one of the three plants inoculated with
$10^{4} \mathrm{CFU}$ of this bacterium at $30 \mathrm{dpi}$, but no bacteria were detected in the other two plants (Fig. 4C). To reduce plant-to-plant experimental variation in virulence assays (23), growth of strain PsvTrp1 was also tested in mixed infections with its parental strain, NCPPB 3335. In vivo CI analysis revealed that the wild-type strain completely out-competed the Psv-Trp1 mutant, as no mutant bacterial cells were recovered after 14 days on LB-Km from any of the five plants tested $(\mathrm{CI}=0)$.

\section{DISCUSSION}

The challenge of this work was to assess the use of in vitro olive plants as a fast and inexpensive method to study pathogenicity and virulence of $P$. savastanoi strains isolated from olive and oleander knots. First, five different wild-type $P$. savastanoi pv. savastanoi isolates were inoculated into olive stem wounds. All of them multiplied and induced swelling of the inoculated tissue. As previously observed in older olive plants, differences in knot formation were observed for the selected strains. These differences, which were reflected in the weight of overgrowths induced by each of the strains used in this study (Fig. 1), may indicate the existence of different virulence factors involved in symptom development among the strains. However, variation of symptoms cannot be attributed to a defect in IAA production by $P$. savastanoi pv. savastanoi strains tested, as all of them produced similar amounts of IAA in the supernatant of 3-day-old SSM-Trp medium (data not shown). We cannot discard that symptomatology differences induced by the strains tested were due to a differential production of phytohormones in the olive tissues, as we did not determine the concentration of IAA and cytokinins produced in vivo by the different strains. Although it has been reported that most $P$. savastanoi pv. savastanoi isolates are highly virulent in olive plants and the severity of the disease is strongly dependent on both the pathogen dose applied to the wounds and plant age, differential interactions between cultivars and strains have also been found using 1- and 3-year-old olive plants (30). In agreement with these authors, the utilization of young olive plants resulted in high susceptibility to olive knot and, as a consequence,
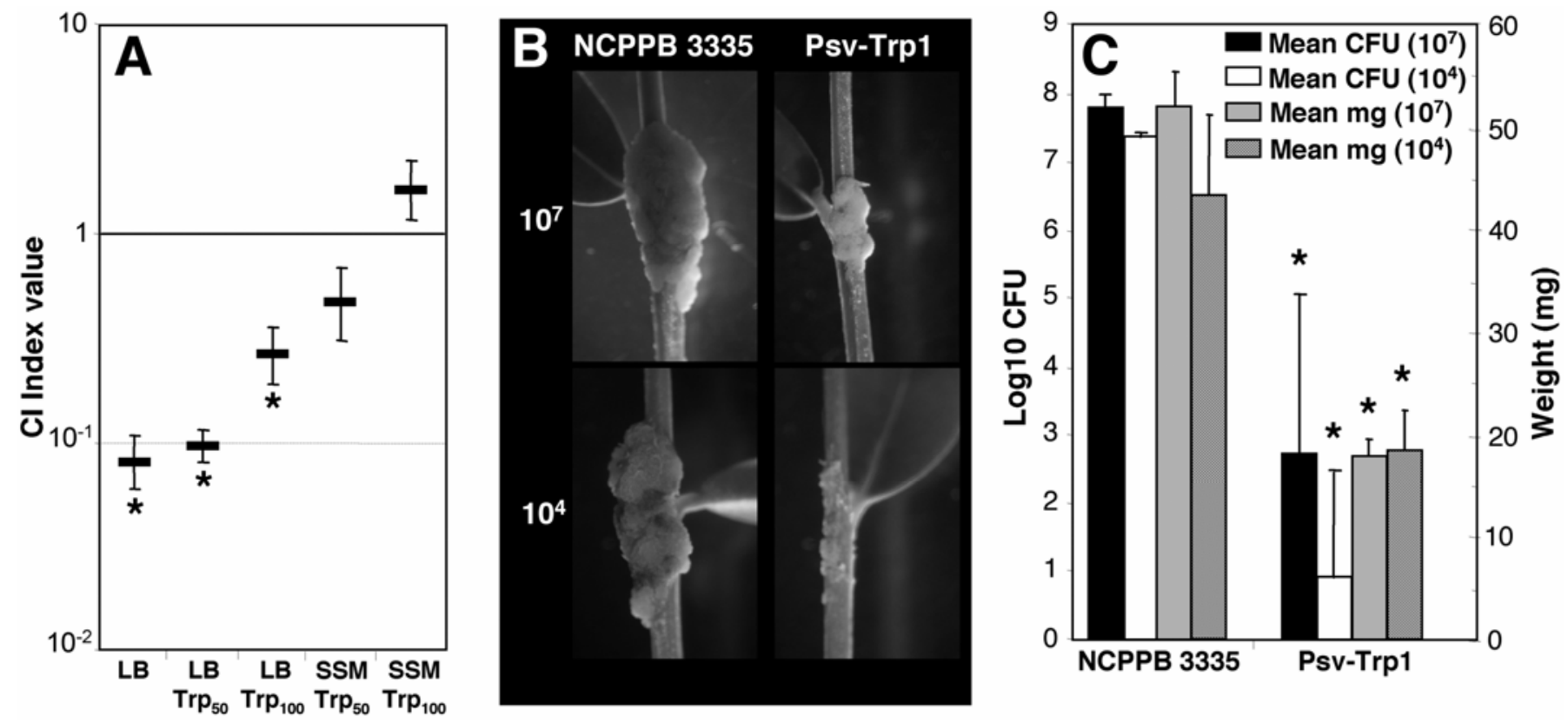

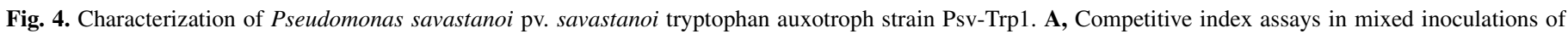

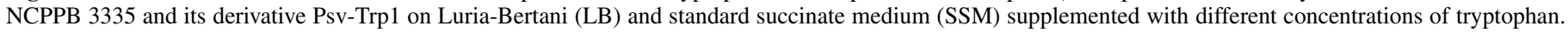

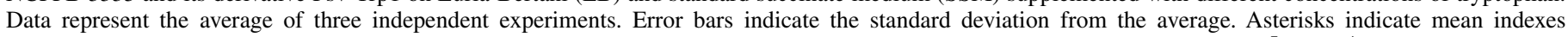

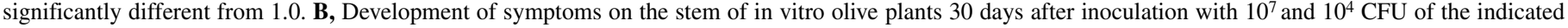

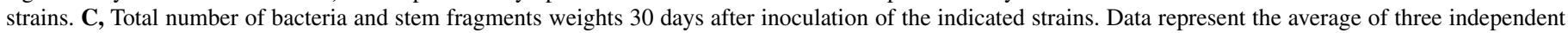

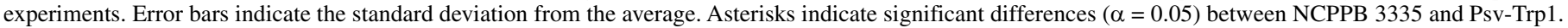


a significant reduction in the time needed for symptoms to appear in comparison with older plants that are commonly used in virulence assays. In fact, knots induced by inoculation of strain NCPPB 3335 with about $10^{7}$ CFU were clearly visible as soon as 7 to 9 dpi (Fig. 2E).

With the exception of an $h r c C$ mutant isolated from $P$. savastanoi pv. savastanoi strain ITM317 and affected in the production of the hypersensitive response and pathogenicity type III secretion system (35), which virulence was not tested in this study, all other $P$. savastanoi pvs. savastanoi and nerii mutants reported so far have shown, in our system, similar virulence phenotypes and growth abilities to those previously reported within the olive tissue of older plants. In fact, symptoms induced in micropropagated olive plants by wild type and mutant strains of $P$. savastanoi pv. nerii affected in the biosynthesis of phytohormones (Fig. 3A) closely resembled those induced in 1-yearold olive and oleander plants (17). Our model system allows rapid screening of a large number of mutant strains and, in addition, offers the possibility of quantifying virulence differences as weight of overgrowths. However, it should be taken into account that young olive tissue does not necessarily reflect knot environment on older olive plants. For this reason, mutants reduced in virulence isolated using our system should later be tested on woody olive stems. Related to this, differential interactions between micropropagated and woody cranberry plants with IAA producing bacteria have been recently reported (41).

Gene-disruption strategies, such as random transposon mutagenesis or gene replacement, are frequently used in animal and plant bacterial pathogens for the isolation of mutants that can be tested for attenuated virulence in model infection systems. The isolation of attenuated mutants thus leads to the identification of genes or operons that are required for survival in the infected host. For this purpose, $P$. savastanoi pv. savastanoi strain NCPPB 3335 , which induced the formation of knots that closely resemble field symptoms (Figs. 1 and 2), was chosen and mutagenized with a collection of STM transposons (15). In a previous study, we confirmed the feasibility of green fluorescent protein tagging and STM by mini-Tn5 transposition in this strain. Integration of this collection of transposons into the genome of NCPPB 3335 occurs randomly, and in most cases at a single site (31), allowing the utilization of this method for identification of virulence genes in $P$. savastanoi pv. savastanoi. In STM, each transposon contains a different DNA sequence tag, which allows mutants to be differentiated from each other. This strategy, which combines the strength of random insertion mutagenesis of the genome with the ability to follow the in vivo fate of a large number of different mutants, is a powerful genetic method to identify genes in pathogens that are required for growth in the host tissues. Although STM has been extensively used for the identification of virulence genes in several animal pathogens, the utilization of this method in $P$. syringae and related pathogens has not yet been reported.

With the exception of the $h r c C$ mutant mentioned above, no other $P$. savastanoi mutants with a growth defect in the host have been described. Because of the very likely close link between the biosynthesis of tryptophan, the precursor of IAA, and virulence of $P$. savastanoi pathovars, we isolated and examined using our model system, $P$. savastanoi pv. savastanoi tryptophan auxotrophs mutants. Among a collection of auxotroph strains isolated by Tn5 mutagenesis in $P$. syringae pv. syringae $\mathrm{B} 728 \mathrm{a}$, a tryptophan auxotroph was shown to exhibit the poorest ability to survive and grow epiphytically on bean leaves $(2,3)$. Three $P$. savastanoi $\mathrm{pv}$. savastanoi mutants unable to grow on unamended SSM were isolated by their ability to grow on SSM containing tryptophan at $40 \mu \mathrm{g} / \mathrm{ml}$; two of them were subsequently characterized and found to contain the STM transposon inserted within the $\operatorname{trpE}$ gene, encoding the $\alpha$-subunit of anthranilate synthase. A higher requirement of tryptophan by $P$. savastanoi pv. savastanoi mutants affected on other steps of the tryptophan biosynthetic pathway could explain this result. In agreement with this hypothesis, among a collection of 11 tryptophan auxotrophs of Rhizobium japonicum, only mutants that had altered anthranilate synthase had similar growth to the wild-type strain on media containing tryptophan at $50 \mu \mathrm{g} / \mathrm{ml}$. All other mutants isolated were blocked at intermediate steps of the pathway and required higher amounts of tryptophan (42). Growth and virulence of Psv-Trp1 on in vitro olive plants was clearly reduced in comparison with the wild-type strain. Tn5-generated auxotroph mutants reduced in virulence have been previously reported in several $P$. syringae pathovars $(1,10)$. A considerable reduction in plant-to-plant variation was observed by CI analysis in mixed infections of the Psv-Trp1 mutant with its parental strain. CI index in mixed infections, a virulence assay widespread after the development of STM and broadly applied to the study of bacterial pathogens in animals, has recently been established as a sensitive and accurate assay for the genetic analysis of phytopathogenic bacteria (23).

Diseases of fruit trees caused by pathovars of $P$. syringae and related pathogens are a major concern in fruit producing areas worldwide because they are exceedingly difficult to control and result in significant economic losses. A deeper understanding and ability to manage $P$. syringae diseases of fruit trees is relevant to the understanding of $P$. syringae diseases of herbaceous hosts, and vice versa (20). However, functional genomic analysis of $P$. syringae pathovars affecting fruit trees is still impaired for most plant-pathogen systems by both the lack of genetically pliable pathogen strains and the development of pathogenicity and virulence tests allowing for inexpensive, fast, reliable and highthroughput screening of a large number of disease-free plants. Results shown here demonstrate the usefulness of in vitro olive plants for the analysis of $P$. savastanoi virulence. Additionally, we have established the basis for the use of mixed infections in combination with STM for identification of genes of this pathogen critical for survival in the host. Our study also encourages utilization of other in vitro-grown fruit trees as model systems for conducting high-throughput functional genomic analysis of $P$. syringae and other related pathogens that can infect woody hosts.

\section{ACKNOWLEDGMENTS}

We thank J. Espartero (Viveros Sevilla S.A., Spain) for providing us with primary olive explants. All P. savastanoi pv. nerii strains included in this work and the collection of Tag-mini-Tn5Km2 transposons were provided by A. Sisto and D. Holden, respectively. We are grateful to M. Duarte for excellent technical assistance and to I. Vidoy for help with micropropagation of olive plants. This project was supported by Spanish MCYT grants AGL2002-02214 and AGL2005-02090, and Junta de Andalucía grant CVI-264.

\section{LITERATURE CITED}

1. Anderson, D. M., and Mills, D. 1985. The use of transposon mutagenesis in the isolation of nutritional and virulence mutants in two pathovars of Pseudomonas syringae. Phytopathology 75:104-108.

2. Beattie, G. A., and Lindow, S. E. 1994. Survival, growth, and localization of epiphytic fitness mutants of Pseudomonas syringae on leaves. Appl. Environ. Microbiol. 60:3790-3798.

3. Beattie, G. A., and Lindow, S. E. 1994. Comparison of the behavior of epiphytic fitness mutants of Pseudomonas syringae under controlled and field conditions. Appl. Environ. Microbiol. 60:3799-3808.

4. Buell, C. R., Joardar, V., Lindeberg, M., Selengut, J., Paulsen, I. T., Gwinn, M. L., Dodson, R. J., Deboy, R. T., Durkin, A. S., Kolonay, J. F., Madupu, R., Daugherty, S., Brinkac, L., Beanan, M. J., Haft, D. H., Nelson, W. C., Davidsen, T., Zafar, N., Zhou, L., Liu, J., Yuan, Q., Khouri, H., Fedorova, N., Tran, B., Russell, D., Berry, K., Utterback, T., Van Aken, S. E., Feldblyum, T. V., D’Ascenzo, M., Deng, W. L., Ramos, A. R., Alfano, J. R., Cartinhour, S., Chatterjee, A. K., Delaney, T. P., Lazarowitz, S. G., Martin, G. B., Schneider, D. J., Tang, X., Bender, C. L., White, O., Fraser, C. M., and Collmer, A. 2003. The complete sequence of the tomato and Arabidopsis pathogen, Pseudomonas syringae pv. tomato DC3000. Proc. Natl. Acad. Sci. USA 100:1018-10186.

5. Caetano-Anollés, G. 1993. Amplifying DNA with arbitrary oligonucleo- 
tide primers. PCR Methods Appl. 3:85-92.

6. Cañas, L. A., and Benbadis, A. 1988. In vitro plant regeneration from cotyledon fragments of olive tree (Olea europaea L.). Plant Sci. 54:65-74.

7. Caponero, A., Contesini, A. M., and Iacobellis, N. S. 1995. Population diversity of Pseudomonas syringae subsp. savastanoi on olive and oleander plants. Plant Pathol. 44:848-855.

8. Comai, L., and Kosuge, T. 1980. Involvement of plasmid deoxyribonucleic acid in indoleacetic acid synthesis in Pseudomonas savastanoi. J. Bacteriol. 143:950-957.

9. Comai, L., and Kosuge, T. 1982. Cloning characterization of iaaM, a virulence determinant of Pseudomonas savastanoi. J. Bacteriol. 149:40-46.

10. Cuppels, D. A. 1986. Generation and characterization of Tn5 insertion mutations in Pseudomonas syringae pv. tomato. Appl. Environ. Microbiol. 51:323-327.

11. Driver, J. A., and Kuniyuki, A. 1984. In vitro propagation of paradox walnut rootstock. HortScience 19:507-509.

12. Espinosa-Urgel, M., Salido, A., and Ramos, J. L. 2000. Genetic analysis of functions involved in adhesion of Pseudomonas putida to seeds. J. Bacteriol. 182:2363-2369.

13. Feil, H., Feil, W. S., Chain, P., Larimer, F., Dibartolo, G., Copeland, A., Lykidis, A., Trong, S., Nolan, M., Goltsman, E., Thiel, J., Malfatti, S., Loper, J. E., Lapidus, A., Detter, J. C., Land, M., Richardson, P. M., Kyrpides, N. C., Ivanova, N., and Lindow, S. E. 2005. Comparison of the complete genome sequences of Pseudomonas syringae pv. syringae B728a and pv. tomato DC3000. Proc. Natl. Acad. Sci. USA 102:1106411069.

14. Gardan, L., Bollet, C., Abughorrah, M., Grimont, F., and Grimont, P. A. D. 1992. DNA relatedness among the pathovar strains of Pseudomonas syringae subsp. savastanoi Janse (1982) and proposal of Pseudomonas savastanoi. Int. J. Syst. Bacteriol. 42:606-612.

15. Hensel, M., Shea, J. E., Gleeson, C., Jones, M. D., Dalton, E., and Holden, D. W. 1995. Simultaneous identification of bacterial virulence genes by negative selection. Science 269:400-403.

16. Hirano, S. S., and Upper, C. D. 2000. Bacteria in the leaf ecosystem with emphasis on Pseudomonas syringae-A pathogen, ice nucleus, and epiphyte. Microbiol. Mol. Biol. Res. 64:624-653.

17. Iacobellis, N. S., Sisto, A., Surico, G., Evidente, A., and Di Maio, E. 1994. Pathogenicity of Pseudomonas syringae subsp. savastanoi mutants defective in phytohormone production. J. Phytopathol. 140:238-248.

18. Janse, J. D. 1981. The bacterial disease or ash (Fraxinus excelsior), caused by Pseudomonas syringae subs. savastanoi pv. fraxini. II. Etiology and taxonomic considerations. Eur. J. Forest Pathol. 11:425-38.

19. Joardar, V., Lindeberg, M., Jackson, R. W., Selengut, J., Dodson, R., Brinkac, L. M., Daugherty, S. C., Deboy, R., Durkin, A. S., Giglio, M. G., Madupu, R., Nelson, W. C., Rosovitz, M. J., Sullivan, S., Crabtree, J., Creasy, T., Davidsen, T., Haft, D. H., Zafar, N., Zhou, L., Halpin, R., Holley, T., Khouri, H., Feldblyum, T., White, O., Fraser, C. M., Chatterjee, A. K., Cartinhour, S., Schneider, D. J., Mansfield, J., Collmer, A., and Buell, C. R. 2005. Whole-genome sequence analysis of Pseudomonas syringae pv. phaseolicola $1448 \mathrm{~A}$ reveals divergence among pathovars in genes involved in virulence and transposition. J. Bacteriol. 187:6488-6498.

20. Kennelly, M. M., Cazorla, F. M., de Vicente, A., Ramos, C., and Sundin, G. W. 2007. Pseudomonas syringae diseases of fruit trees: Progress toward understanding and control. Plant Dis. 91:4-17.

21. King, E. O., Ward, M. K., and Raney, D. E. 1954. Two simple media for the demonstration of pyocyanin and fluorescin. J. Lab. Clin. Med. 44:301307.

22. Lavermicocca, P., Lonigro, S. L., Valerio, F., Evidente, A., and Visconti, A. 2002. Reduction of olive knot disease by a bacteriocin from Pseudomonas syringae pv. ciccaronei. Appl. Environ. Microbiol. 68:1403-1407.

23. Macho, A. P., Zumaquero, A., Ortiz-Martín, I., and Beuzón, C. R. 2007. Competitive index in mixed infections: a sensitive and accurate assay for the genetic analysis of Pseudomonas syringae-plant interactions. Mol. Plant Pathol. 4:437-450.

24. Magie, A. R., and Wilson, E. E. 1962. Expression of virulence among isolates of Pseudomonas savastanoi from olive and oleander. Phytopathology 52:741.

25. Mencuccini, M., and Rugini, E. 1993. In vitro shoot regeneration from olive cultivar tissues. Plant Cell Tiss. Org. 32:283-288.

26. Meyer, J. M., and Abadía, M. A. 1978. The fluorescent pigment of Pseudomonas fluorescens: Biosynthesis, purification and physiochemical properties. J. Gen. Microbiol. 160:319-328.

27. Miller, J. H. 1972. Experiments in Molecular Genetics. Cold Spring Harbor Laboratory, Cold Spring Harbor, NY.

28. Mugnai, L., Surico, G., and Iacobellis, N. S. 1993. Response of explants and cultured cells of oleander to inoculation with strains of Pseudomonas syringae subs. savastanoi. Petria 3:27-40.

29. Ortíz-Martín, I., Macho, A. P., Lambersten, L., Ramos, C., and Beuzon, C. R. 2006. Suicide vectors for antibiotic marker exchange and rapid generation of multiple knockout mutants by allelic exchange in Gramnegative bacteria. J. Microbiol. Methods 67:395-407.

30. Penyalver, R., García, A., Ferrer, A., Bertolini, E., Quesada, J. M., Salcedo, C. I., Piquer, J., Pérez-Panadés, J., Carbonell, E. A., del Río, C., Caballero, J. M., and López, M. M. 2006. Factors affecting Pseudomonas savastanoi pv. savastanoi plant inoculations and their use for evaluation of olive cultivar susceptibility. Phytopathology 96:313-319.

31. Pérez-Martínez, I., Rodríguez-Moreno, L., Matas, I. M., and Ramos, C. 2007. Strain selection and improvement of gene transfer for genetic manipulation of Pseudomonas savastanoi isolated from olive knots. Res. Microbiol. 158:60-69.

32. Pérez-Martínez, I., Zhao, Y., Murillo, J., Sundin, G. W., and Ramos, C. 2008. Global genomic analysis of Pseudomonas savastanoi pv. savastanoi plasmids. J. Bacteriol. 190:625-635.

33. Rugini, E. 1984. In vitro propagation of some olive (Olea europaea L.) cultivars with different root-ability, and medium development using analytical data from developing shoots and embryos. Sci. HorticAmsterdam 24:123-134

34. Sambrook, J., and Russell, D. W. 2001. Molecular Cloning: A Laboratory Manual. 3rd ed. Cold Spring Harbor Laboratory, Cold Spring Harbor, NY.

35. Sisto, A., Cipriano, M. G., and Morea, M. 2004. Knot formation caused by Pseudomonas syringae subsp. savastanoi on olive plants is hrpdependent. Phytopathology 94:484-489.

36. Sisto, A., Morea, M., Zaccaro, F., Palumbo, G., and Iacobellis, N. S. 1999 Isolation and characterization of Pseudomonas syringae subs. savastanoi mutants defective in hypersensitive response elicitation and pathogenicity. J. Phytopathol. 147:321-330.

37. Smidt, M., and Kosuge, T. 1978. The role of indole-3-acetic acid accumulation by alpha-methyl tryptophan-resistant mutants of Pseudomonas savastanoi in gall formation in oleander. Physiol. Plant Pathol. 13:203214.

38. Surico, G. 1993. Scanning electron microscopy of olive and oleander leaves colonized by Pseudomonas syringae subsp. savastanoi. J. Phytopathol. 138:31-40.

39. Surico, G., Iacobellis, N. S., and Sisto, A. 1985. Studies on the role of indole-3-acetic acid and cytokinins in the formation of knots on olive and oleander plants by Pseudomonas syringae pv. savastanoi. Physiol. Plant Pathol. 26:309-320.

40. Sutic, D., and Dowson, D. J. 1963. The reaction of olive, oleander, and ash cross inoculated with some strains and forms of Pseudomonas savastanoi (Smith Stevent). Phytopathol. Z. 46:305-314.

41. Vasanthakumar, A., and McManus, P. S. 2004. Indole-3-acetic acidproducing bacteria are associated with cranberry stem gall. Phytopathology 94:1164-1171.

42. Wells, S. E., and Kuykendall, D. 1983. Tryptophan auxotrophs of Rhizobium japonicum. J. Bacteriol. 156:1356-1358. 